\title{
Luxímetro Didático Comparativo: abordagem pedagógica em sala de aula
}

\section{Comparative Didactic Luxmeter: pedagogical approach in the classroom}

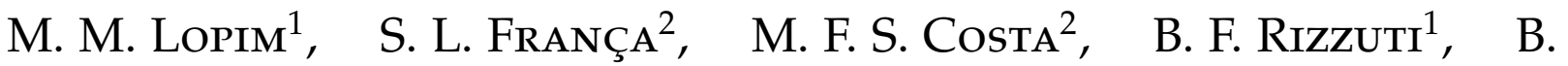 \\ GONÇALVES $^{2}$
}

${ }^{1}$ Departamento de Física, Universidade Federal de Juiz de Fora.

${ }^{2}$ Núcleo de Física - Laboratório de Inovação Tecnológica Instituto Federal Sudeste de Minas Gerais.

\section{Resumo}

Esse trabalho tem por objetivo a apresentação das etapas de uma sequência didática aplicada em sala de aula baseada no conceito de eficiência energética de lâmpadas. Para tal, foi utilizado um produto educacional experimental nomeado Luxímetro Didático Comparativo. O pluralismo metodológico foi escolhido para a elaboração desta sequência. Ela foi aplicada para turmas tanto de segundo quanto de terceiro anos do ensino médio, indicando possíveis atitudes produtivas dos aprendizes.

Palavras-chave: Sequência Didática. Luxímetro. Eficiência energética. Pluralismo metodológico. 


\begin{abstract}
The main objective of this work is to present the stages of a didactic sequence applied in the classroom, based on the energetic efficiency concept of lamps. For this, we have used an experimental educational product, called Luximetro Didactico Comparativo. Methodological pluralism was chosen for the elaboration of this sequence. It was applied to both second and third years of High School, indicating possible productive attitudes of students.
\end{abstract}

Keywords: Didactic Sequence. Luximeter. Energetic efficiency. Methdological pluralism.

\title{
I. INTRODUÇÃO
}

Existe um consenso entre educadores em ciência de que a conexão entre os assuntos presentes no do dia-a-dia dos estudantes com o material didático usual, como livros e apostilas, pode ser profícua no processo de ensino-aprendizagem (BRASIL, 2002).

O aprendizado no Ensino de Física tem apresentado em suas principais características: a memorização e a aplicação automáticas de fórmulas e a repetição de procedimentos. A aplicação exclusiva dessa prática pedagógica tem indicado abstração e aprendizagens superficiais nos discentes. De acordo com os PCN+ (BRASIL, 2002),

“Na escola, de modo geral, o indivíduo interage com um conhecimento essencialmente acadêmico, principalmente através da transmissão de informações, supondo que o estudante, memorizando-as passivamente, adquira o conhecimento acumulado".

É comum os estudantes na disciplina de Física questionarem: "Por que preciso estudar Física?". De acordo com as Orientações Educacionais Complementares aos Parâmetros Curriculares Nacionais, as competências específicas desenvolvidas em sala de aula através dos conteúdos desta disciplina devem possibilitar o entendimento de fenômenos naturais e tecnológicos presentes no cotidiano dos alunos e abranger a compressão sobre fenômenos científicos de microestruturas, derivadas dos estudo sobre a Mecânica Quântica e macroestruturas, vinculadas aos estudos sobre a compreensão do universo.

Seguindo esta linha, apresenta-se aqui a aplicação de uma sequência didática desenvolvida a partir do tema geral de eficiência energética. A base para estruturação das aulas foi o pluralismo metodológico (LABURÚ C. E.; ARRUDA; NARDI, 2003), onde se evidencia fortemente dois métodos, a aprendizagem significativa (AUSUBEL, 1968) e o ensino por investigação (CAPECCHI; CARVALHO, 2006; CARVALHO et al., 2010; PIAGET, 1970; SEDANO; CARVALHO, 2017; CARVALHO, 2018). Além disso, utilizou-se também como ferramenta um produto educacional experimental. Trata-se de um luxímetro capaz de comparar a eficiência energética de lâmpadas diferentes, em função da determinação de grandezas físicas distintas, a saber, temperatura, corrente elétrica e poder de iluminação. $\mathrm{O}$ produto será nomeado LuDiCo, acrônimo para luxímetro didático comparativo. Os detalhes técnicos de sua construção e funcionamento podem ser vistos em (LOPIM et al., 2018). 
Como resultados, almeja-se que essa sequência didática propicie aos estudantes: a identificação de grandezas físicas utilizadas em aparelhos elétricos e tecnológicos, o conceito de eficiência vinculado ao consumo de energia das lâmpadas, especificidades no estudo de proporcionalidade entre frequência e energia da luz visível, identificação de fenômenos físicos no funcionamento de dispositivos elétricos residenciais e o desenvolvimento da Física nos processos econômicos, tecnológicos e de qualidade de vida.

Adotando-se estratégias para a existência de aprendizagem, esta sequência didática estruturou-se em várias metodologias pedagógicas, evitando o reducionismo teórico com a finalidade de dinamizar as aulas em que foram executadas a aplicação da sequência. Pressupondo as diversidades e a não padronização existente em sala de aula, este trabalho propõe um incentivo a compreensão dos fenômenos físicos pela investigação (CARVALHO, 2018), a utilização da linguagem científica, sua contextualização com o cotidiano, motivação nas aulas e entendimento da importância do aprendizado da disciplina de Física. Este trabalho é resultado de uma dissertação do Mestrado Nacional Profissional em Ensino de Física.

O trabalho será então dividido da seguinte maneira. Na próxima Seção, o LuDiCo será brevemente descrito. Continuando, na Seção III, apresenta-se a metodologia e referencial teórico do trabalho. A Seção IV dedica-se à apresentação da sequência didática e sua aplicação é exposta na Seção V. Na próxima Seção, os resultados e análise da aplicação da sequência didática são apresentados, ficando a Seção VII para a conclusão.

\section{Apresentando o LuDiCo}

Essa Seção é dedicada à breve descrição do aparato experimental LuDiCo. Maiores detalhes de funcionamento e operação podem ser vistos em (LOPIM et al., 2018). Recomendase também o vídeo explicativo <https:/ / youtu.be/xZuHVwBLN2E>.

Trata-se de um quadro de madeira, com três bocais para lâmpadas de uso doméstico, um amperímetro, um termômetro infravermelho e um fotosensor associado a uma escala de LEDs (light emitting diode) alto brilho. O LuDiCo coleta informações como corrente e temperatura de lâmpadas (nesse trabalho, foram utilizadas uma lâmpada incandescente, uma fluorescente compacta e uma de LED), além de fornecer também o poder de iluminação das lâmpadas a partir do fotosensor que indica a capacidade de luminosidade. Quanto mais LEDs acesos na escala, maior poder de iluminação. Além disso, os LEDs estão dispostos com as cores do espectro visível. Assim, quanto maior a luminosidade de uma lâmpada, os LEDs acendem-se com cores de frequência cada vez mais alta. Destaca-se que foram utilizados apenas LEDs com encapsulamento transparente, com uma única frequência de emissão, caracterizando a cor de cada um deles. Além disso, cada LED deste tipo acende com uma tensão mínima característica: abaixo do valor de corte de diferença de potencial, o LED está apagado. Acima do valor de corte, o LED acende; aumentar a tensão aumenta a intensidade, entretanto o LED não muda de cor.

Um último detalhe técnico de funcionamento do LuDiCo será discutido aqui. Ele tem papel fundamental na Aula 4 da sequência didática que será apresentada. $\mathrm{O}$ aparato possui dois circuitos distintos, sem conexão elétrica entre os dois. A Figura 1 mostra explicitamente: um dos circuitos, o de potência, é alimentado por uma tomada e é responsável por acender 
as lâmpadas utilizadas no aparelho, com correntes da ordem de Ampères. Já o outro, o de controle, é alimentado por uma fonte de corrente contínua, sendo responsável por alimentar os LEDs, com correntes da ordem de miliampères.

É importante que seja dada muita atenção a esse ponto quando é feita a apresentação do equipamento. Caso não fique claro que a corrente que é medida no Amperímetro não é a que passa pelos LEDs, os alunos podem chegar a uma conclusão errada sobre a relação de energia com frequência. Eles podem fazer a suposição errada que quanto mais corrente passa pelo LED, maior a frequência da luz emitida na escala do LuDiCo, quando a grandeza relevante ali é a voltagem (o LED é um componente eletrônico não ôhmico). Um estudante poderia até chegar a escrever a relação matemática na forma esperada entre energia e frequência, mas com um erro grave de associar grandezas características de dois corpos diferentes: as lâmpadas e os LEDs.

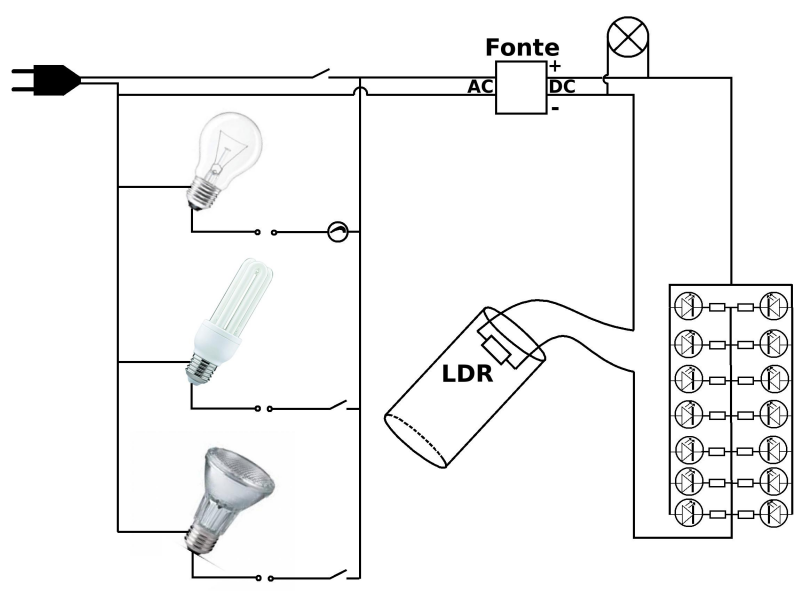

Figura 1: Circuitos de potência e controle do LuDiCo.

A conexão entre os circuitos é dada pelos LDRs, funcionando como um regulador de tensão. Ao serem iluminados, sua resistência baixa, aumentando a tensão que alimenta os LEDs, fazendo-os acender gradativamente.

A Figura 2 mostra uma visão geral do aparato. (a) mostra a medição do poder de iluminação de uma lâmpada incandescente. Já em (b), apresenta-se a medição de temperatura de uma lâmpada fluorescente compacta. 


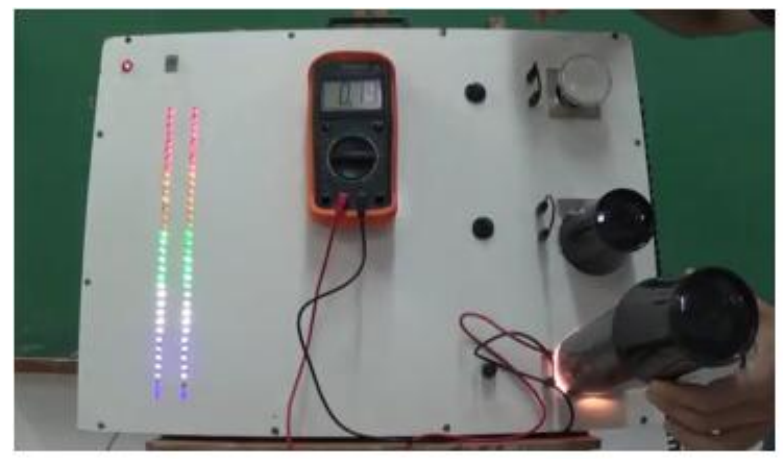

(a)

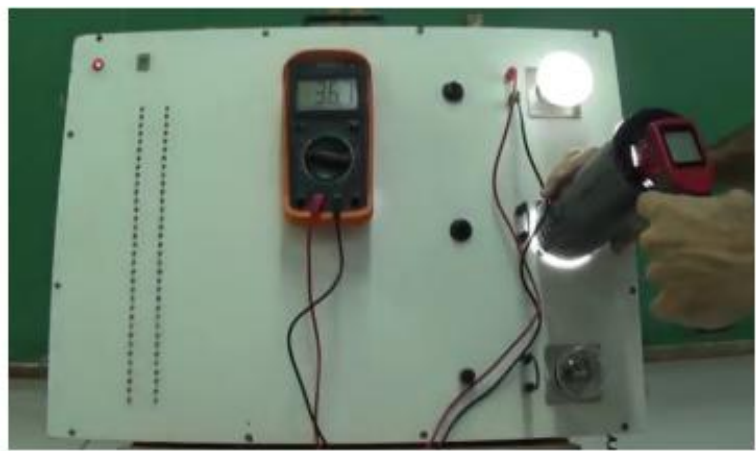

(b)

Figura 2: LuDiCo em funcionamento.

\section{REFERENCIAL TEÓRICO}

Apresenta-se aqui o referencial teórico que suporta o trabalho. Descreveremos minuciosamente sua conexão com cada etapa da sequência didática, que será detalhada na próxima Seção.

O Anarquismo Epistemológico, defendido por Feyerabend (FEYERABEND, 2010; RÉGNER, 1996), afirma que as regras estruturadas por metodologia única inibe as condições para o desenvolvimento do pensamento criativo e o despertar das capacidades críticas. Consonante com esta teoria, a sequência didática planejada é composta por aulas baseadas com referenciais construtivistas e interacionistas (CARVALHO et al., 2010), propondo sempre a investigação de fenômenos científicos através do estudo da eficiência energética de lâmpadas. Espera-se que os discentes através desta sequência, baseada em metodologia plural, realizem as atividades propostas no experimento e estruturem o conhecimento dos fenômenos físicos para alcançarem aprendizagem, respeitando sempre suas concepções e percepções.

As práticas pedagógicas em que a aprendizagem é construída centrada no aluno e a pedagogia objetivista em que o professor é transmitivista do conhecimento, apresentam-se ineficientes no Ensino de Ciências quando praticadas em caráter exclusivo (LABURÚ C. E.; ARRUDA; NARDI, 2003).

Para a sequência didática deste trabalho foram adotadas diferentes abordagens didáticas em sala de aula, devido às complexidades que esta apresenta reconhecendo que o processo de ensino-aprendizagem é mutável, complexo e não trivial.

A aprendizagem significativa de David Ausubel (AUSUBEL, 1968) baseia suas práticas entre a interação de conhecimentos prévios e novos conhecimentos, a fim de alcançar uma estabilidade cognitiva. Através de um subsunçor ou ideia-âncora, um novo conhecimento pode ser subordinando às concepções primárias com o propósito de desenvolver a aprendizagem de um novo conceito.

Na primeira etapa da sequência didática, propõe-se que o estudante demonstre por escrito, um conhecimento prévio estável e estruturado a fim de que novas aprendizagens sejam assimiladas como um processo natural, espontâneo. Portanto considera-se que a apresentação de um primeiro subsunçor é de extrema relevância para a aprendizagem de 
novos conhecimentos que serão estudados durante as aulas. A metodologia de aprendizagem significativa é caracterizada pela organização entre o primeiro subsunçor e os subsunçores que se apresentarão durante todo o processo de aprendizagem.

Antes de falarmos da segunda, terceira e quarta etapas da sequência, ressaltamos que a quinta é definida pela análise de uma possível indicação de aprendizagem, através de relatórios escritos pelos alunos nesta etapa com a comparação dos que foram escritos na etapa inicial, com a finalidade de reconhecer demonstrações de novos saberes.

Retornando à ordem da sequência, através das medições de corrente elétrica e temperatura que ocorrem na segunda etapa, espera-se que os estudantes por investigação, reconheçam as relações entre as medições realizadas destas duas grandezas físicas. $\mathrm{O}$ professor estimula a participação ativa dos estudantes, adotando práticas que possibilitam as interações entre os alunos e também entre professor-aluno. $\mathrm{O}$ docente deve estar atento a sempre expressar o problema em pauta, a fim de proporcionar argumentações sobre os fenômenos físicos estudados. É válido destacar a importância da investigação para o Ensino de Física (SEDANO; CARVALHO, 2017), pois através das relações encontradas nas medições entre corrente elétrica e temperatura, o aluno tem a oportunidade de interagir com o experimento, classificar as informações obtidas e com os dados obtidos nas medições conceituar o fenômeno do efeito Joule e inicialmente justificar suas hipóteses sobre a eficiência das lâmpadas apresentadas.

A terceira etapa é descrita pelo estudo das frequências da luz visível, através de figura contendo o espectro eletromagnético. A turma, em discussão, responderá ao seguinte questionamento: "As ondas eletromagnéticas no celular podem ser consideradas como luz? Explique com suas palavras". Segundo Vygotsky em sua Teoria de Aprendizagem Sócio-Cultural (BORIN M.; GIORDAN, 2012), a aprendizagem é uma atividade conjunta e colaborativa entre os alunos e o professor assume uma postura privilegiada sendo o mediador. Considerando que os processamentos que constituem a aprendizagem são alcançados individualmente, nesta etapa o professor atua como um moderador auxiliando os alunos a localizarem as informações sobre o espectro eletromagnético, avaliá-las e compartilhá-las com a turma.

O docente mostra-se atento às explicações apresentadas pelos alunos, direcionando-os a substituírem suas linguagens para a linguagem científica. No final desta etapa a questão proposta, é respondida contendo todas informações relevantes debatidas pelos discentes. Os conceitos aprendidos são relatados individualmente por escrito. O propósito desta etapa é fornecer aos estudantes um contato inicial com a associação entre cor/frequência e energia na luz visível.

A quarta etapa caracteriza-se por utilizar o produto experimental LuDiCo para realizar as medições sobre a luminosidade das lâmpadas e encontrar a relação de proporcionalidade entre frequência e energia. Iniciam-se as investigações: os estudantes em grupos comparam medidas e descrevem o problema.

Após a análise e entendimento do questionamento, com o intermédio das medições anotadas na tabela, o professor sugere a construção de um gráfico. Estudando a linguagem gráfica, os alunos iniciam a construção conceitual do fenômeno. As medições obtidas proporcionam a construção da linguagem matemática que demonstra o conceito de relação entre as grandezas: energia e frequência. 
Todo esse processo investigativo apresenta suas dificuldades por isso é importante ressaltar a transição da linguagem gráfica para a fenomenológica, nessa fase da sequência, pois desta forma torna-se necessária a interação direta entre professor e alunos. Neste momento é esperado que o aluno esteja pronto para descrever seu aprendizado sobre os conceitos físicos estudados no experimento proposto, assim como também caracterizar com linguagem científica a eficiência das lâmpadas. Ao final da aula, cada estudante escreve seu relatório.

A última etapa caracteriza-se pela realização de um problema intitulado "Conta de luz". A turma dividiu-se em grupos a fim de realizar um problema do cálculo de gasto financeiro das três lâmpadas do experimento, oportunizando a análise e a ressignificação de suas concepções. As relações entre o Ensino de Ciências, Tecnologias e Sociedade podem apresentar abstração devido às suas complexidades (CARVALHO et al., 2010). Realizar a conexão entre as atividades aprendidas pelos alunos com um novo conhecimento para o meio social é função do professor, respeitando sempre a dignidade, ideologias e crenças dos estudantes, mas sempre os guiando a refletirem nas alternativas de mudanças que resultam em melhoria para o indivíduo e sociedade em que vive.

\section{A SEQUÊNCIA DIDÁTICA}

A sequência didática que vamos apresentar corresponde à aplicação em sala de aula do produto LuDiCo. O produto educacional, com sua respectiva aplicação compõem parte de uma dissertação de Mestrado Nacional Profissional em Ensino de Física desenvolvida no Polo XX, na cidade XX, Estado XX. A sequência didática foi dividida em seis aulas de cinquenta minutos cada, detalhadas neste trabalho.

\section{IV.1. Aula 1}

Na primeira aula, os alunos recebem uma folha com a atividade inicial, na qual visualizam figuras de três lâmpadas: incandescente, fluorescente compacta e LED. Cada uma apresenta respectivamente, o valor de potência dissipada $(W)$ e de temperatura $\left({ }^{\circ} \mathrm{C}\right)$, e uma fotografia relacionada à utilização das respectivas no cotidiano, conforme a Figura 3. Nessa primeira etapa é relevante que o docente conheça os subsunçores presentes na estrutura cognitiva dos estudantes, em relação às informações que lhes são apresentadas. Na parte posterior da atividade os estudantes descrevem o conhecimento que possuem sobre as propriedades e características de cada uma das lâmpadas, demonstrando suas ideias-âncora e desta forma caracterizam quais, dentre as três lâmpadas apresentadas possui a maior eficiência. Buscando instigar os alunos, a professora fez os seguintes questionamentos:

- Qual das três lâmpadas possui maior luminosidade?

- Financeiramente, qual das três lâmpadas consome mais?

- Qual das três lâmpadas tem maior consumo energético?

- Qual das três lâmpadas é a mais eficiente?

- Caso você conheça, cite outras utilizações das três lâmpadas no cotidiano. 


\section{Atividade Inicial}

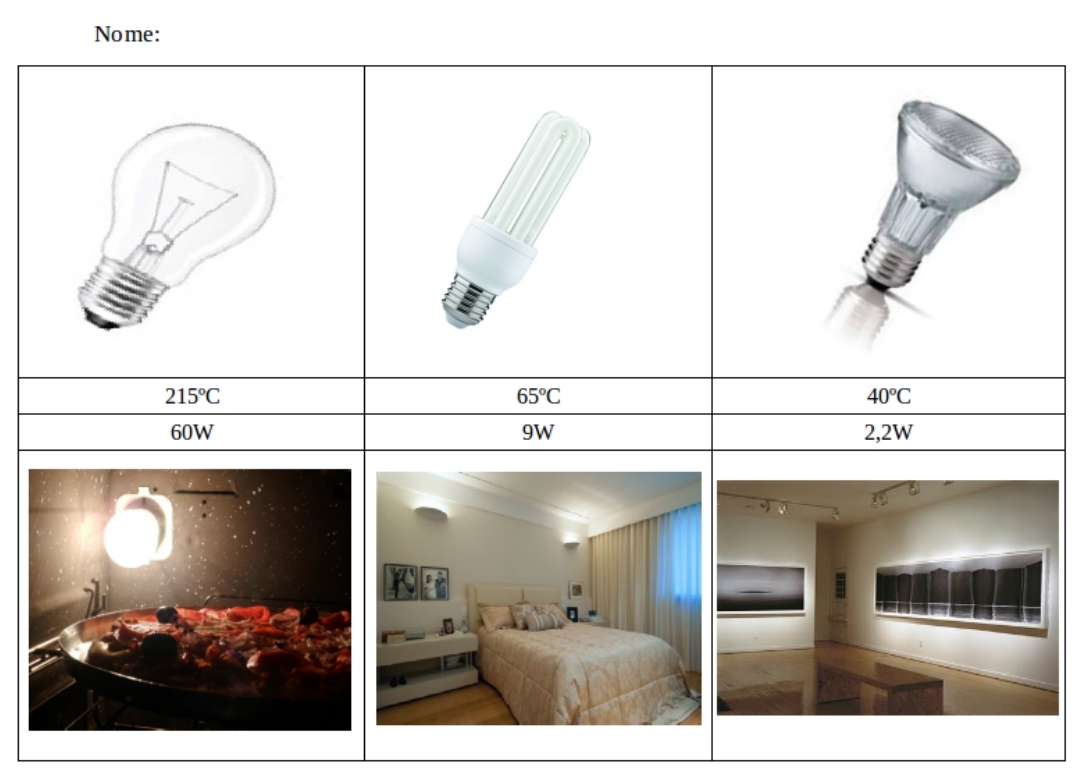

Figura 3: Imagens utilizadas na atividade inicial.

\section{IV.2. Aula 2}

A segunda etapa da sequência didática é realizada com a utilização do produto educacional experimental LuDiCo. Os discentes fazem as medidas de duas grandezas físicas, corrente elétrica e temperatura de cada lâmpada, registrando as medidas obtidas em uma tabela, como exibida na Figura 4. Analisando e investigando as medidas encontradas, os estudantes

\begin{tabular}{|c|c|c|}
\hline \multicolumn{3}{|c|}{ EXPERIMENTO LÚDICO } \\
\hline \multicolumn{3}{|c|}{$\begin{array}{l}\text { ATENÇÃO: PARA ESTE TRABALHO NÃO } \\
\text { CORRETAS, NEM INCORRETAS. VOCÊ DE } \\
\text { REPOSTA DIFERENTE DAS RESPOSTAS DOS } \\
\text { EXPERIMENTO E RESPONDA. }\end{array}$} \\
\hline \multicolumn{3}{|c|}{$\begin{array}{l}\text { Vamos realizar a medição da temperatura, utilizando o termômetro de } \\
\text { infravermelho, e da corrente elétrica, utilizando o amperímetro para as três } \\
\text { lâmpadas: Incandescente, Fluorescente e LED. }\end{array}$} \\
\hline Lâmpada & Temperatura $\left({ }^{\circ} \mathrm{C}\right)$ & Corrente Elétrica (A) \\
\hline \multicolumn{3}{|c|}{ Incandescente } \\
\hline \multicolumn{3}{|c|}{ Fluorescente } \\
\hline \multicolumn{3}{|l|}{ LED } \\
\hline \multicolumn{3}{|c|}{$\begin{array}{l}\text { Analise suas medidas e responda com suas palavras: qual lâmpada é a mais } \\
\text { eficiente e qual lâmpada é a menos eficiente? }\end{array}$} \\
\hline
\end{tabular}

Figura 4: Tabela de medidas e atividade proposta na segunda aula.

buscam identificar regularidades, relacionando-as com a respectiva lâmpada. Espera-se que eles consigam caracterizar e responder ao questionamento relativo sobre a eficiência das lâmpadas estudadas, relatando as conclusões finais desta etapa com o propósito de estabelecer a eficiência das lâmpadas. As regularidades obtidas nas medições das grandezas 
físicas corrente elétrica e temperatura são induzidas a serem questionadas pelos estudantes para a estruturação do conceito sobre o efeito Joule e como ele conecta-se com o conceito de eficiência energética. É importante que os alunos aprendam os conceitos científicos e construam habilidades cognitivas a partir dos processos que envolvem a atividade científica, tais como: resolução de um problema, levantamento de hipóteses, análise de dados, discussão de resultados, argumentação entre outras (SOLINO A. P.; FERRAZ; SASSERON, 2015).

\section{IV.3. Aula 3}

Na terceira etapa da sequência didática, o estudo é realizado em relação ao espectro eletromagnético. Entrega-se aos alunos uma figura do espectro (veja a Figura 5) e através desta o professor apresenta uma situação problema que propõe e possibilita ao aluno a aprendizagem pré-estabelecida pela sequência. Almeja-se que na interação aluno-aluno, os

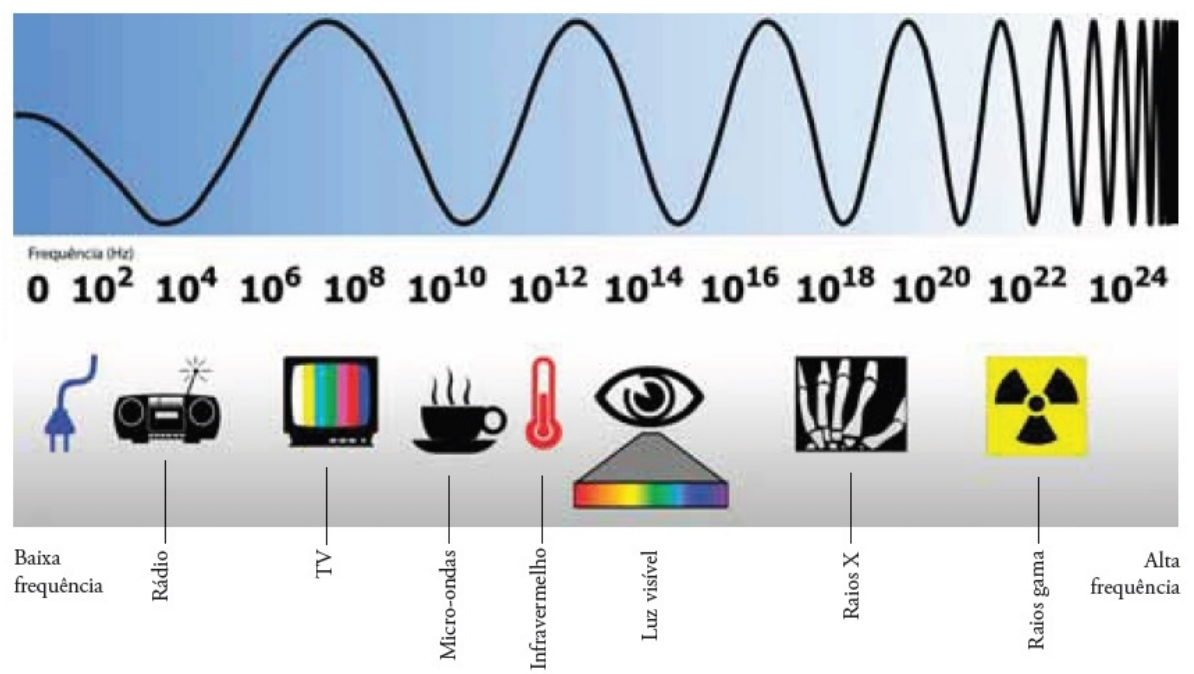

Figura 5: Espectro eletromagnético. Fonte: <http://carlamcoelho.blogspot.com/2015/10/ espectro-eletromagnetico.html>.

mesmos debatam as concepções prévias acerca da figura do espectro. Após as hipóteses e/ou situações problema apresentadas e apontadas pelos estudantes, o professor deve ressaltar os conceitos sobre a grandeza física frequência $(\mathrm{Hz})$ e o estudo da luz visível no espectro eletromagnético. Salienta-se que os conceitos apresentados pelo professor objetivam estruturar a aprendizagem dos alunos em relação ao trabalho nesta sequência. Ao final da aula propõe-se a produção de um relato escrito em que se aborde os conceitos apresentados. O maior intuito desta etapa consiste em correlacionar as cores do espectro visível da luz com a frequência correspondente. A razão disso é que o LuDiCo possui uma escala de LEDs ligada diretamente com a energia luminosa liberada por cada lâmpada estudada. Em atividades investigativas os debates ou interações discursivas são ocasiões em que os alunos conversam entre si, fundamentando o que querem enunciar através das trocas de ideias e identificando seus conhecimentos prévios em relação ao questionamento proposto e através da mediação do professor o conhecimento científico se organiza (SASSERON, 2008). 


\section{IV.4. Aula 4}

Além das atividades propostas inicialmente, há também uma atividade ligada com mecânica quântica. O LuDiCo permite, de forma qualitativa, compreender a conexão entre energia e frequência da sequência de LEDs. Os alunos recebem uma tabela mostrada na Figura 6, em que anotam os valores de correntes elétricas que atravessam a lâmpada incandescente, anotando também quais cores de LED são acesos no painel. A coleta de dados é feita da seguinte maneira: encobre-se a lâmpada incandescente dimerizável com o fotosensor de LDRs e rotaciona-se o dimmer vagarosamente, controlando a luminosidade da lâmpada.

\begin{tabular}{|c|c|}
\hline \multicolumn{2}{|c|}{$\begin{array}{l}\text { Experimento LuDiCo } \\
\text { Regule o dimmer para que a lâmpada incandescente apresente o maior } \\
\text { brilho. Diminua a corrente gradativamente evagarosamente, anotando } \\
\text { correntes e marcando as cores acesas na tabela abaixo. }\end{array}$} \\
\hline Corrente (Energia) & Cor (Frequência) \\
\hline & 000000 \\
\hline & 0000000 \\
\hline & 000000 \\
\hline & 00000 \\
\hline & 000000 \\
\hline & 0000000 \\
\hline & 000000 \\
\hline & 000000 \\
\hline & 000000 \\
\hline & 0000000 \\
\hline
\end{tabular}

Figura 6: Tabela de medidas e atividade proposta na quarta aula.

Assim cada uma das sete cores de LEDs alto brilho da escala acende conforme o valor da corrente elétrica averiguada no amperímetro se altera. Esses valores são anotados. Na tabela, encontra-se a relação entre a corrente elétrica que alimenta a lâmpada incandescente e as cores de LEDs alto brilho acesos da escala. Neste ponto, a professora reforçou com os estudantes o detalhe de que o aparato possui dois circuitos distintos, como exposto na Figura 1. O primeiro (de potência), em que foram medidas a corrente das lâmpadas, da ordem de Ampères e anotados na primeira coluna. E um segundo, de controle, eletricamente independente do primeiro, contendo a escala de LEDs, referindo-se à segunda coluna. Ela ainda deixou claro que estavam procurando associar a energia elétrica total que chega à sequência de LEDs com a frequência da luz emitida por cada componente luminoso deste conjunto. Isso foi feito explicando que, neste caso, essa energia é diretamente proporcional à voltagem neste circuito específico, controlada pela incidência luminosa no LDR.

Propõe-se a construção de um gráfico com objetivo de permitir que os estudantes concluam a relação existente entre frequência de LEDs acesos com a corrente que atravessa a lâmpada incandescente, investigando a linguagem matemática que essas medidas e o desenho do gráfico sugere. O gráfico demonstra uma função monótona que pode ser descrita da seguinte forma: quando o valor de corrente elétrica aumenta, mais energia luminosa é depositada sobre o sensor e com isso, LEDs com cores de frequência cada vez mais alta 
acendem. É importante que o professor instigue os alunos a evidenciar, a partir da leitura do gráfico, o fenômeno concluído pelos estudantes.

Concluindo esta etapa, o docente induz, de forma qualitativa, que energia é proporcional a frequência $(E \sim v)$. Nesta etapa também é realizada a medida da capacidade de iluminação de cada uma das lâmpadas. Ao encobrir cada lâmpada com o fotosensor a lâmpada que acender mais cores de LEDs alto brilho na escala será a que possui maior "poder de iluminação". Um breve relatório deve ser escrito pelos alunos sobre as evidências descobertas nesta etapa. A aprendizagem em ciências se apresenta muitas vezes complexa no âmbito escolar devido às abstrações que os fenômenos apresentam. É comum que os professores recorram à transposição didática como auxílio para o entendimento do conceito científico (TAUCHEN, 2012). Sendo assim, ao se utilizar a transposição didática como instrumento teremos, um conceito que ao ser transferido, de um contexto ao outro, passa por modificações. Ao ser ensinado, todo conceito mantém semelhanças com a ideia originalmente presente em seu contexto da pesquisa, porém adquire outros significados próprios do ambiente escolar no qual será analisado (BROCKINGTON G.; PIETROCOLA, 2005).

\section{IV.5. Aula 5}

A quinta etapa da aplicação da sequência didática do LuDiCo é a apresentação final de todo o experimento. Nesta etapa os discentes registram através da escrita de texto expondo todas as observações e conclusões sobre as atividades e aprendizagens que obtiveram. $\mathrm{O}$ texto deve ser escrito individualmente e evidenciar todo o aprendizado construído sobre o que foi proposto.

Espera-se que neste texto final os alunos indiquem qual a lâmpada mais eficiente, elaborando uma resposta em que abordem os fenômenos estudados nas etapas anteriores; citem o caráter quântico observado de maneira qualitativa onde se relaciona energia luminosa emitida pela lâmpada incandescente e absorvida pelo fotosensor (representada pelo valor de corrente elétrica) e cores de LEDs alto brilho acesos na escala (representando a frequência característica das cores dos LEDs). Cabe destacar que tudo que o discente julgar interessante em todo processo da sequência didática pode e deve ser escrito neste relato. Em atividades investigativas o aluno deve se expressar através da escrita individual, o ensino de ciências deve priorizar em como escrever ciência, oportunizando aos alunos trabalhar funções cognitivas específicas, pois o discurso escrito é convergente, focalizado.

\section{IV.6. Aula 6}

Esta etapa caracteriza-se pela resolução do "Problema da conta de luz" com a intenção de destacar a diferença entre o gasto econômico de cada lâmpada e a relação direta entre os fenômenos físicos estudados nas etapas anteriores. A questão apresenta uma situação hipotética, em que três pessoas deixam lâmpadas dos tipos estudados durante a sequência acesas por determinado tempo. Os estudantes precisam determinar o consumo de cada uma delas. Junto ao problema, encontra-se uma conta fictícia da fornecedora mineira de energia elétrica, veja a Figura 7. 
A resolução de problemas que envolvem situações cotidianas apresentam uma forma didática de apresentar a Matemática como relação de linguagem de conceitos de Física e propõe que o pensamento científico deve lançar ideias e argumentações sobre como se pode interpretar fenômenos científicos e fenômenos sociais que abrangem este tipo de linguagem.

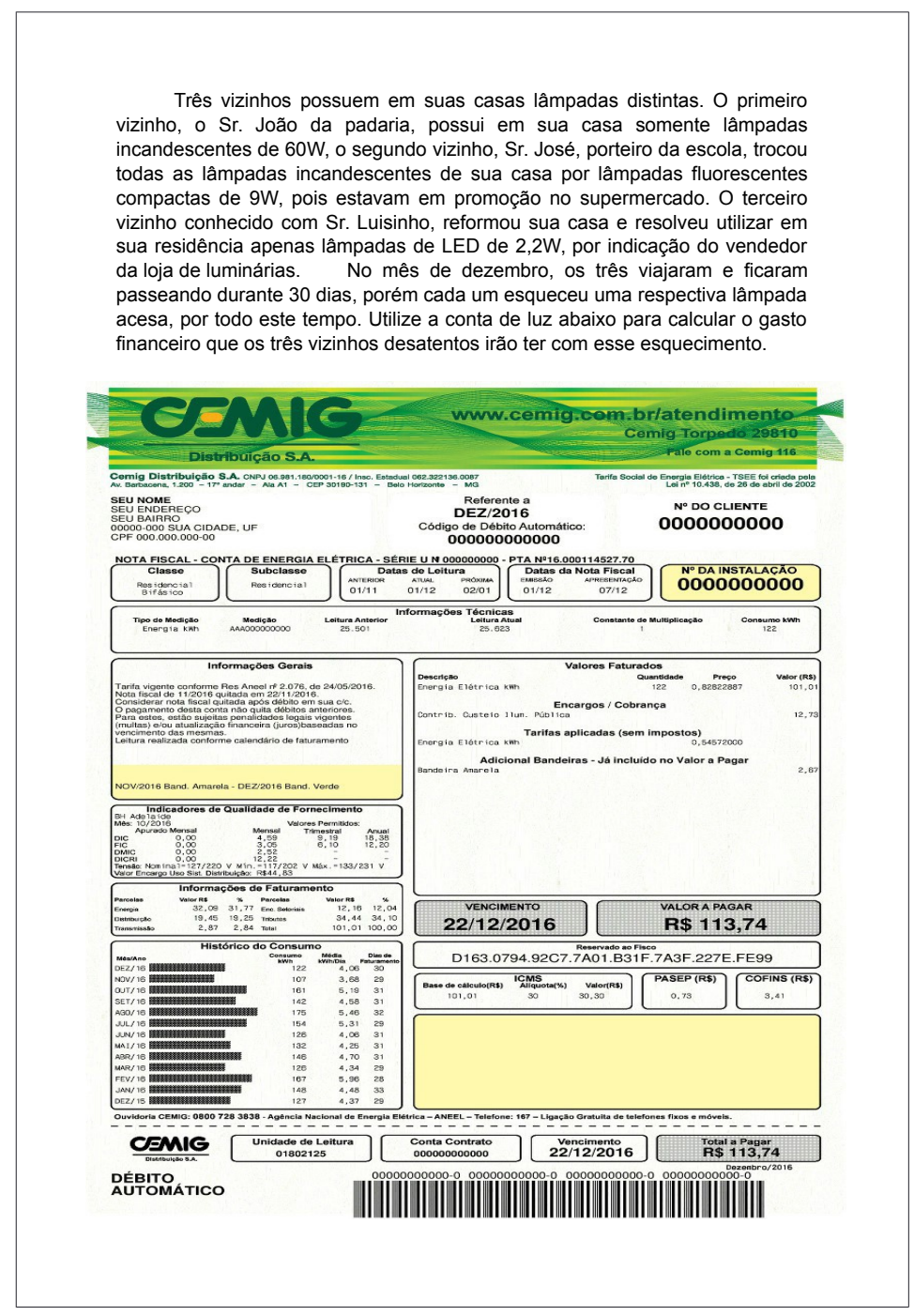

Figura 7: Conta da CEMIG alterada para utilização em atividade da sequência.

\section{Aplicação do luDiCo em Sala de Aula}

A sequência didática foi aplicada em uma escola estadual situada na região oeste da cidade de Juiz de Fora - Minas Gerais no mês de agosto do ano de dois mil e dezoito, para duas turmas de Ensino Médio (regular). A turma do Terceiro Ano (composta por vinte alunos) tinha como característica perceptível a apatia pelas aulas de Física e o desinteresse em realizar avaliações externas (PISM, ENEM, entre outras). Já a classe do Segundo Ano 
(composta por vinte cinco alunos) tinha como característica a frequência, a participação e a indisciplina.

Inicialmente, a aplicação da sequência didática aconteceria apenas para o último ano do ensino médio, mas seguindo as orientações da supervisão da escola, por corresponder expectativas do plano anual de curso apresentado à escola (Terceiro Ano) e pelo fato da sequência didática conter atividades de caráter investigativo, a sequência foi aplicada também à turma do Segundo Ano. As atividades de cada etapa da sequência didática eram guardadas separadamente, para que os alunos tivessem acesso aos seus registros. Nas próximas subseções detalharemos cada etapa de aplicação.

\section{V.1. Primeira etapa}

A primeira aplicação nas duas turmas tinha como objetivo coletar os subsunçores existentes e de forma textual os relatos dos alunos sobre as concepções primárias em relação ao que estavam sendo questionados. Inicialmente eles demonstraram reações de estranhamento diante da escrita de um texto na aula de Física em que o docente não solicitou o uso do caderno utilizado na disciplina ou qualquer livro didático. Após mostrar as lâmpadas e identificá-las, apresentando-as e tornando-as acessíveis aos alunos, a professora motivou-os lendo o questionário escrito no quadro, reforçando as questões, explicando e afirmando que não se tratava de uma avaliação e sim de uma expressão individual acerca dos saberes e concepções primárias que eles possuíam em relação às lâmpadas apresentadas na atividade inicial. Atenta, a professora buscou mediar o desenvolvimento das atividades propostas orientando a escrita textual a qual evidenciava a captação dos subsunçores.

\section{V.2. Segunda etapa}

A segunda etapa da sequência didática iniciou-se com a apresentação do produto educacional experimental LuDiCo. Posteriormente, cada turma foi dividida em grupos de cinco alunos. Naturalmente, a docente explicou como eles realizariam as medições de corrente elétrica com o amperímetro e temperatura com o termômetro de infravermelho em cada lâmpada. A coleta de temperatura é retratada na Figura 8. Os grupos apresentaram boa organização na realização dessa atividade, enquanto um aluno fazia as medições, os demais observavam atentamente. Organizados, os estudantes anotavam as medidas e discutiam as relações de proporção entre elas. Antes de finalizar a atividade, eles respondiam ao questionamento: Qual das três lâmpadas é a mais eficiente e a menos eficiente? Cada aluno com sua tabela de medidas em mãos expunha seus registros e considerações. Verificou-se que as duas medidas da lâmpada incandescente eram muito superiores em relação às medidas na lâmpada de LED e que a lâmpada fluorescente também apresentava medidas muito inferiores à lâmpada incandescente e pouco superiores à lâmpada de LED.

A partir das regularidades apresentadas por estas medidas, a professora lançou uma discussão com objetivo de evidenciar o fenômeno do efeito Joule.

É importante que essa atividade possibilite ao estudante, mesmo que de forma não consciente, a superação de concepções empírico-indutivistas da ciência. Ao resolverem questões experimentais propostas pelo professor, os alunos levantam suas hipóteses baseadas 


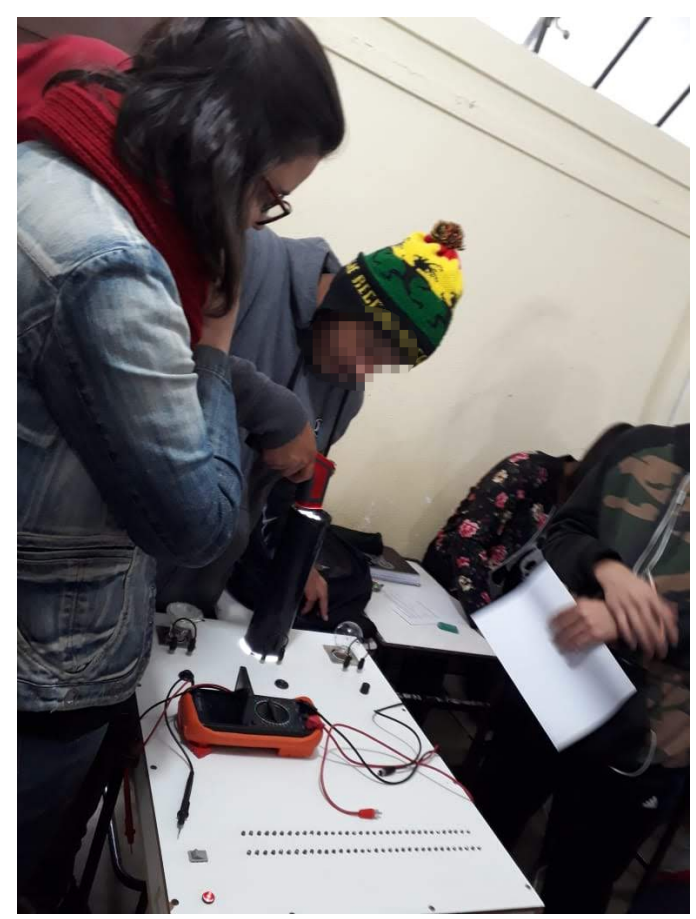

Figura 8: Medidas realizadas com o termômetro de infravermelho durante a segunda etapa.

em seus conhecimentos prévios onde essas são submetidas à prova, mediante as análises das medidas verificadas.

\section{V.3. Terceira etapa}

Com a terceira etapa da sequência didática apresentou-se o estudo direcionado do espectro eletromagnético em uma relação aluno-aluno e após professor-aluno. Cada aluno recebeu um desenho do espectro, com o seguinte questionamento: "As ondas eletromagnéticas no celular podem ser consideradas como luz? Explique com suas palavras."

Para responder ao questionamento, os alunos deveriam investigar o problema proposto, elaborando a partir das discussões entre os alunos da turma, as suas próprias questões. Inicialmente os argumentos levantados pelos alunos em relação ao questionamento eram pouco expressivos. A partir dessa percepção a professora aprofundou os pontos abordados na discussão entre os estudantes, incentivando a discussão onde expunham suas ideias. A docente levou em consideração que os alunos estavam prontos a trabalhar com o problema apresentado, e após respeitar as hipóteses e soluções do questionamento, a professora se torna a mediadora sem abandonar seu principal objetivo, o de ensinar. Em ambas as turmas em que a sequência foi aplicada os debates se tornaram muito interessantes demonstrando concepções espontâneas notáveis. Destaca-se aqui, que na discussão entre os grupos, ao olhar a figura do espectro eletromagnético, os estudantes concluíram que o telefone celular também funciona por captação de ondas, pois o associaram com a informação que possuíam sobre o funcionamento de um rádio.

Ao retomar a organização da turma, a professora trouxe as considerações relevantes apresentadas pelos alunos para a linguagem científica, respondendo ao questionamento 
e direcionando o estudo do espectro para análise da luz visível e revisando o conceito de frequência e energia. As duas turmas afirmaram que já haviam estudado os conceitos no primeiro ano do ensino médio. A atividade terminou com o registro sobre o questionamento proposto e o que foi conceituado nesta etapa com a mediação da professora, que incentivava a escrita em uma linguagem científica.

\section{V.4. Quarta etapa}

A quarta etapa baseava-se na atividade experimental investigativa. Os alunos trabalharam no LuDiCo, em seus grupos, fazendo suas medidas de corrente elétrica, enquanto rotacionavam o dimmer vagarosamente, variando a luminosidade da lâmpada incandescente coberta com o fotosensor de LDRs. Assim os estudantes assinalavam para cada medida de corrente as cores de LEDs alto brilho acesos na escala. Essa etapa pode ser vista na Figura 9. Os outros grupos assistiam e naturalmente contribuíam opinando, principalmente

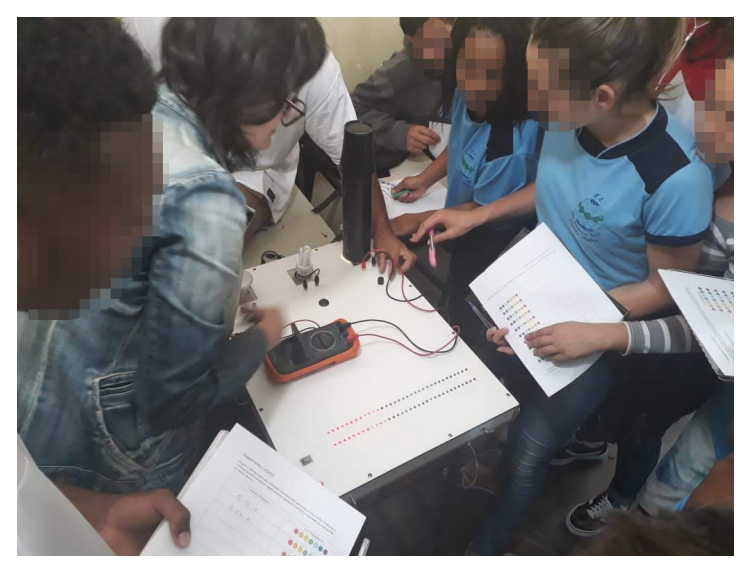

Figura 9: Discentes coletam informações como corrente nas lâmpadas e cores de LEDs acesos.

em relação à intensidade de brilho dos LEDs. A interação entre os alunos era notada nas discussões que precedia a construção de suas hipóteses. Após as medições, individualmente e com suas respectivas tabelas, os alunos investigaram as regularidades entre as medidas de corrente elétrica e cores de LEDs alto brilho acesas na escala. Posteriormente indagados sobre a relação entre as medidas, conclusões acerca do resultado experimental começaram a serem apresentadas. Uma folha quadriculada foi entregue com a finalidade da construção do gráfico: Corrente $\times$ Cor. Novamente a professora enfatizou que o produto possui dois circuitos independentes (o de potência e o de controle), não havendo conexão elétrica entre eles. Os estudantes foram também relembrados que a corrente medida era única e exclusivamente aquela que alimentava a lâmpada incandescente, sendo totalmente independente da corrente necessária para acender os LEDs.

Cabe destacar que os alunos demonstraram muitos obstáculos e dificuldades na construção do gráfico, a maioria não conhecia a folha quadriculada e sua utilização para fins matemáticos. A realização desta atividade só se tornou possível com auxílio da professora.

Com os gráficos construídos, a docente analisou a função encontrada permitindo que os estudantes destacassem a relação entre corrente elétrica e cor de LEDs alto brilho acesos. Através do gráfico e em conjunto, concluíram que para valores mais altos de corrente elétrica 
mais cores de LEDs alto brilho eram acesos na escala. É importante destacar que através das discussões originadas no estudo do gráfico, relacionou-se a corrente elétrica na lâmpada incandescente com energia, (energia luminosa coletada pelo fotosensor de LDRs), a cor de LEDs alto brilho acesos no painel e sua respectiva frequência.

Desta forma a professora orientou que fossem trocadas as grandezas físicas nos eixos do gráfico, o eixo das ordenadas que era corrente elétrica passou a representar energia, e no eixo das abcissas a troca foi cor por frequência, necessariamente nesta ordem. Neste momento então os alunos obtiveram um gráfico Energia $\times$ Frequência e a professora ensinou sobre o comportamento quântico da escala de LEDs alto brilho e de forma qualitativa puderam concluir analisando o gráfico que existe uma relação entre energia e frequência. A Figura 10 retrata um dos gráficos construídos pelos estudantes durante esta etapa.

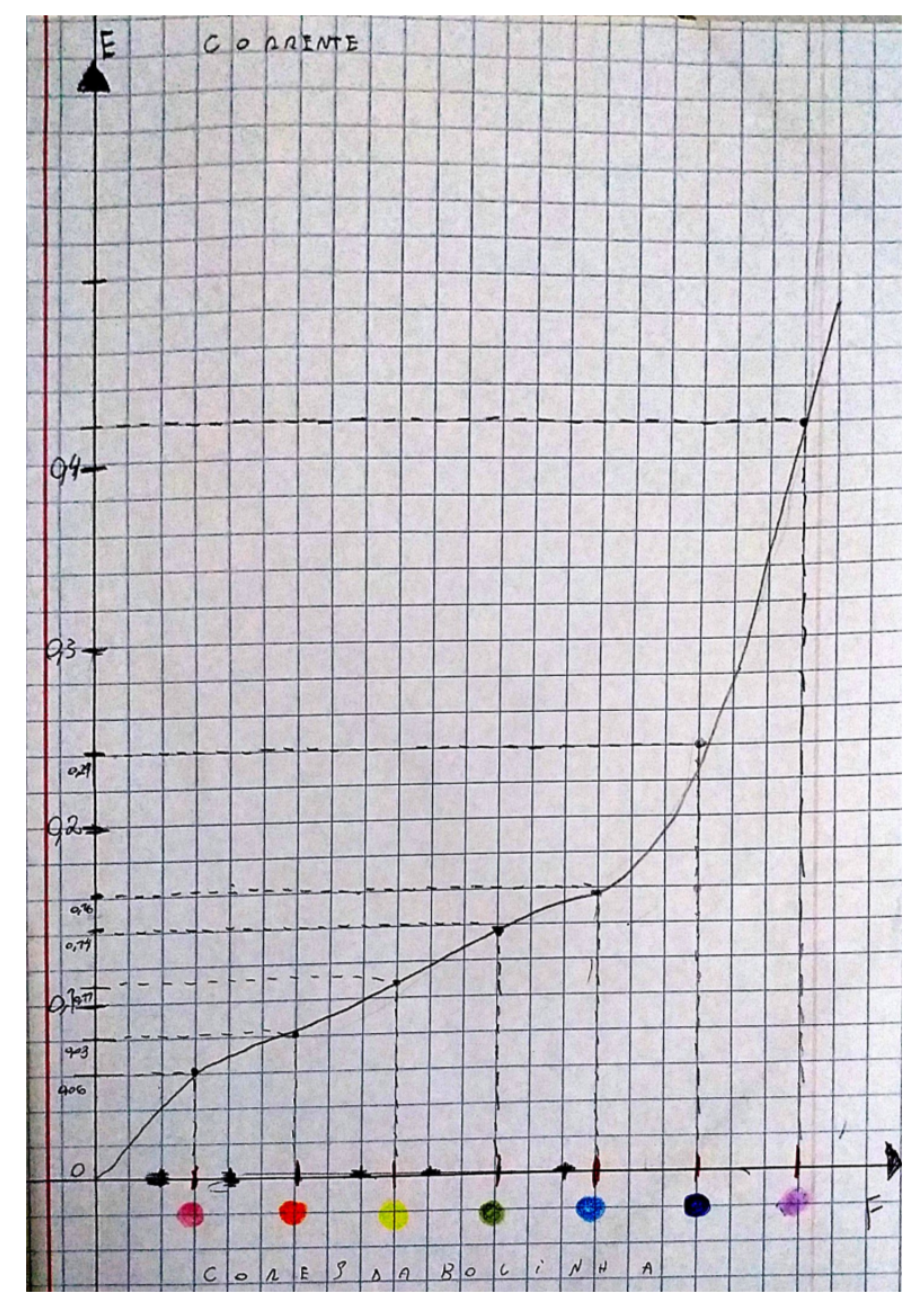

Figura 10: Foto do gráfico feito pelos alunos durante a quarta etapa.

Para finalizar esta etapa os alunos retornaram ao experimento LuDiCo, encobriram as três lâmpadas com o fotosensor de LDR para medir qual delas possui maior "poder de iluminação", ou seja, a lâmpada que acender mais LEDs alto brilho na escala. Os alunos ficaram atraídos por essa medição e concluíram que a lâmpada de LED e incandescente iluminam de forma igual, pois acendem todos os LEDs alto brilho da escala; a lâmpada 
fluorescente brilha um pouco menos, pois segundo os relatos dos alunos os LEDs violeta não acenderam. No final desta etapa, os estudantes escreveram um registro evidenciando o fenômeno físico estudado e as medidas realizadas em sala de aula.

\section{V.5. Quinta etapa}

Nessa etapa os alunos escreveram um texto final, a fim de demonstrarem as aprendizagens obtidas com o experimento LuDiCo.

Nessa aula é importante salientar que não existiram debates, nem diálogos entre eles. Os estudantes puderam utilizar os registros das atividades das etapas anteriores, exceto a primeira, que serve como indicadora dos organizadores prévios. Nesse relatório final eles deveriam indicar qual a lâmpada era a mais eficiente, justificando com os fenômenos físicos estudados no experimento e mencionar a relação entre energia e frequência existentes, indicando qual lâmpada comprariam. A docente estimula uma escrita com linguagem científica. O ensino da escrita com termos científicos é importante para uma enculturação em ciências e também a escrita é uma complementação de todas as argumentações e resultados realizados em sala de aula de forma que pode-se desenvolver habilidades e interesses nos alunos em ciências, nesta sequência didática especificamente na Física.

\section{V.6. Sexta etapa}

A sexta etapa é a resolução do problema da conta de luz, apresentado anteriormente. Os alunos calculam o consumo financeiro de cada lâmpada acesa no período de trinta dias. Os discentes dividiram-se em grupos e revisaram o conceito de potência dissipada, sob a orientação da professora. Eles descobriram que o produto dos valores das grandezas, potência dissipada e tempo em que a lâmpada permaneceu acesa, resulta no valor de energia consumida. Assim é possível realizar o cálculo do gasto financeiro de cada lâmpada, pois a conta de luz da prestadora de energia elétrica fornece os valores necessários para a finalização do problema.

Estes cálculos mostraram que a lâmpada de LED apresentava um valor de custo financeiro bem inferior em relação às outras duas lâmpadas. Após a maioria dos discentes afirmar que comprariam a lâmpada fluorescente compacta, apesar de reconhecerem a melhor eficiência da lâmpada de LED, esta atividade tem o propósito de promover questionamentos e reflexão nos alunos, em outras palavras instigá-los, orientando-os a saber que o conhecimento é muitas vezes desenvolvido por ideias controversas.

\section{Resultados e AnÁlise de dados}

A análise foi realizada através dos relatórios presentes nas etapas da sequência didática, buscando avaliar o desenvolvimento de cada aluno, onde constatou-se a interação e estruturação do seu pensamento.

$\mathrm{Na}$ primeira atividade em que foram analisadas com objetivo de apurar as ideiasâncoras ou subsunçores, em relação às três lâmpadas estudadas no LuDiCo, obteve-se os seguintes dados. De um total de quarenta e cinco alunos participantes, seis estudantes 
$(13,33 \%)$ relataram em seus textos, a importância de conhecer o aquecimento da lâmpada por intermédio de sua medida de temperatura, bem como sua potência dissipada (citando a relação energia por tempo) e assim poder caracterizar sua eficiência. A maioria dissertou outras utilidades das lâmpadas, além das que estavam indicadas nas figuras. Nenhum aluno, citou no texto qual das lâmpadas considerava mais eficiente.

Na segunda etapa, em que foram feitas medidas de corrente elétrica e temperatura, trinta e cinco alunos $(77,8 \%)$ indicaram a lâmpada de LED como a mais eficiente, justificando que suas medidas de corrente elétrica e temperatura eram as mais baixas, cinco alunos $(11,1 \%)$ indicaram a fluorescente justificando que ela apresentou boas medidas de corrente elétrica e temperatura e possuía a melhor iluminação. Os outros cinco alunos $(11,1 \%)$ restantes indicaram que a lâmpada incandescente era a mais eficiente justificando que ela possui mais energia por possuir maior aquecimento e desta forma ter mais potência de luz. Os alunos que relataram as lâmpadas de LED e fluorescente como as mais eficientes. Indicaram que a menos eficiente era a lâmpada incandescente, justificando que seu aquecimento consome mais energia, portanto, gerando uma conta de luz mais cara. Nota-se aqui a conexão que os estudantes fizeram do efeito Joule com a conta de luz.

A terceira etapa se concretiza pelo viés construtivista e interacionista que possui e o professor sendo o mediador e direcionador dos conceitos físicos que devem ser estudados na aula. Os alunos registraram nos relatórios seus saberes sobre o espectro eletromagnético ao fim de aula, demonstrando entendimento sobre luz visível e frequência. Os relatórios, em sua maioria, apresentaram termos científicos abordados durante a aula.

A quarta etapa é caracterizada pela construção do gráfico. O relatório final dos estudantes mostrou na escrita o resultado: maior a corrente elétrica, mais cores de LEDs alto brilho acesos na escala. E o conhecimento do novo fenômeno em que energia conecta-se com frequência. Como foi citado que essa é uma demonstração de Física Quântica, vários estudantes citaram essa constatação em seus relatórios; a professora ao apontar essa relação, explicou a diferenciação entre Física Clássica e Física Quântica, questionamento pertinente e de interesse de muitos alunos.

A quinta e última etapa, é a apresentação textual de todas as conclusões das etapas da sequência didática e os novos saberes adquiridos. Nela, foram apresentados três questionamentos para a análise de aprendizagem significativa: mencionar a relação entre energia e frequência e como ela foi deduzida na sequência didática; responder qual a lâmpada mais eficiente e justificar, usando uma linguagem científica; responder qual das três lâmpadas comprariam.

A maioria dos estudantes explicou a relação entre energia e frequência em sua forma qualitativa, como foi apresentada pela docente. Eles citaram a relação entre as medidas de corrente elétrica e cores de LEDs alto brilho acesos na escala, a partir da construção do gráfico. Pode-se concluir sobre o aprendizado do efeito quântico em questão como ideia-âncora, que se inicia na terceira etapa no estudo da luz visível com interações de novos conhecimentos. As medidas de corrente elétrica e cores LEDs alto brilho na escala, e a relação entre essas duas grandezas finalizam essa conclusão demonstrando o aprendizado com a construção do gráfico, em que a linguagem matemática justifica todo o conceito.

No texto final quarenta alunos $(88,88 \%)$, afirmaram que a lâmpada mais eficiente é a de LED, citando que ela possui as menores medidas de temperatura, corrente elétrica, acende 
todos os LEDs na escala e portanto, possuindo boa iluminação. Citaram também que ela gasta menos financeiramente e energeticamente. Esses alunos apresentaram subsunçores diferenciáveis do que haviam demonstrado na atividade inicial e estão aptos a novas aprendizagens, indicando possível aprendizagem significativa dos conceitos propostos. Os outros quatro alunos restantes indicaram a lâmpada incandescente como a mais eficiente, justificando que ela possui maior potência de luz, por causa de seu aquecimento. Um outro aluno indicou a fluorescente, sem justificativa. Para esses cinco alunos (11,12\%) podemos citar ausência de subsunçor necessário para a construção do aprendizado. O professor deve suprir essa ausência oferecendo um significado pessoal que requer um envolvimento professor-aluno, de forma que o aluno sinta-se propenso aos processos de aprendizagens.

No questionamento em que indagava qual das lâmpadas os estudantes comprariam, trinta alunos $(66,67 \%)$ indicaram a lâmpada fluorescente, doze estudantes $(26,66 \%)$ a lâmpada de LED e apenas três alunos $(6,66 \%)$ comprariam lâmpadas incandescentes. Os números desse questionamento não condizem com os resultados apresentados em relatórios em relação à eficiência das lâmpadas. Os estudantes explicaram que suas casas possuem lâmpadas fluorescentes e que as lâmpadas de LEDs são de um custo financeiro bem superior às outras. Dessa forma somente pessoas com melhor poder aquisitivo poderiam tê-las. Esse resultado relata uma concepção de subjetividade pois apresenta a noção do indivíduo que não é absolutamente fixa e estável. Essa noção se relaciona ao meio cultural e saberes vindos desse e suas expressões. Uma das atribuições ao Ensino de Física é transpor o novo conhecimento para a vida social.

\section{CONCLUSÃo}

Este trabalho apresentou a aplicação em sala de aula de um produto inovador, o Luxímetro Didático Comparativo. O produto experimental LuDiCo propôs atividades inovadoras a fim de construir o interesse. Foram utilizadas aulas com questões investigativas que propunham a discussão sobre a eficiência energéticas entre as lâmpadas: incandescente, fluorescente e LED, instigando os estudantes a se sentirem motivados. Em suas análises textuais, ao final de cada etapa, os estudantes demonstraram que abandonavam suas concepções ingênuas e adotavam progressivamente o desenvolvimento da linguagem científica. Ao concluírem a sequência didática a maioria dos estudantes indicou a lâmpada de LED como a mais eficiente. Cinco estudantes participantes do processo não explicitaram compreensão aos conceitos físicos abordados pois indicaram as lâmpadas incandescente e fluorescente como as mais eficientes. Um aluno evidenciou que lâmpada mais eficiente é a incandescente justificando em seu relato escrito que esta possui maior "potência de luz". Por isso é relevante ressaltar a não existência de um método pedagógico que consiga abranger a todos, considerando que todas as metodologias possuem suas respectivas restrições e que os estudantes possuem condições iniciais diversas, assim como, formação de estrutura cognitiva, motivacional e emocional distintas. Outro fator notado foi a discordância entre os resultados apresentados e os comportamentais, a maioria dos alunos que indicaram a lâmpada LED como mais eficiente, não a utilizaria para consumo. Analisando esse relato de consumo que os alunos apresentaram, uma nova aula foi realizada para que os estudantes comparassem os diferentes valores do gasto econômico das lâmpadas e assim refletissem 
sobre suas ideias pré estabelecidas e as relacionando com os resultados observados no LuDiCo. Pode se concluir que o alinhamento entre as atividades experimentais do LuDiCo associadas a uma prática metodológica plural apresentaram resultados satisfatórios para a consolidação das aprendizagens dos fenômenos físicos que foram investigadas.

\section{AgRAdecimentos}

O presente trabalho foi realizado com apoio da Coordenação de Aperfeiçoamento de Pessoal de Nível Superior - Brasil (CAPES) - Código de Financiamento 001.

Agradecemos à FAPEMIG pelo apoio financeiro.

\section{REFERÊNCIAS}

AUSUBEL, D. P. Educational Psychology: A Cognitive View. New York: Holt, Rinehart and Winston, 1968. 53, 56

BORIN M.; GIORDAN, M. Percepções na teoria sociocultural de vigotski: uma análise na escola. Alexandria Revista de Educação em Ciência e Tecnologia, v. 5, n. 1, p. 113-125, 2012. 57

BRASIL. PCN+ ENSINO MÉDIO - Orientações Educacionais Complementares aos Parâmetros Curriculares Nacionais. Brasília: Ministério da Educação e Cultura - SEMTEC, 2002. 53

BROCKINGTON G.; PIETROCOLA, M. Serão as regras da transposição didática aplicáveis aos conceitos de física moderna? Investigação em Ensino de Ciências, v. 10, n. 3, p. 387-404, 2005. 62

CAPECCHI, M. C. V. M.; CARVALHO, A. M. P. Atividade de laboratório como instrumento para abordagem de aspectos da cultura científica em sala de aula. Pro-Posições, v. 17, n. 1, p. 137-153, 2006. 53

CARVALHO, A. M. P. Fundamentos teóricos e metodológicos do ensino por investigação. Revista Brasileira de Pesquisa em Educação em Ciências, v. 18, n. 3, p. 765-794, 2018. 53, 54

CARVALHO, A. M. P. et al. Ensino de Física. São Paulo: Cengage Learning, 2010. 53, 56, 58

FEYERABEND, P. Against Method: Outline of an Anarchistic Theory of Knowledge. New York: Verso Books, 2010. 56

LABURÚ C. E.; ARRUDA, S. M.; NARDI, R. Pluralismo metodológico no ensino de ciências. Ciência e Educação, v. 9, n. 2, p. 247-260, 2003. 53, 56

LOPIM, M. M. et al. LÚdico - luxímetro didático comparativo. Física na Escola, v. 16, n. 2, p. 40-44, 2018. 53, 54

PIAGET, J. Structuralism. New York: Harper \& Row, 1970. 53

RÉGNER, A. C. K. Feyerabend e o pluralismo metodológico. Epistéme: Filosofia e História das Ciências em Revista, v. 1, n. 2, p. 61-78, 1996. 56 
SASSERON, L. H. Interações discursivas e investigação em sala de aula: o papel do professor - Texto 6. 2008. Disponível em: <https://edisciplinas.usp.br/acessar/> - Acesso em 07 ago. 2020. 60

SEDANO, L.; CARVALHO, A. M. P. Ensino de ciências por investigação: Oportunidades de interação social e sua importância para a construção da autonomia moral. Alexandria: Revista de Educação em Ciência e Tecnologia, v. 10, n. 1, p. 199-220, 2017. 53, 57

SOLINO A. P.; FERRAZ, A. T.; SASSERON, L. H. Ensino por investigação como abordagem didática: Desenvolvimento de práticas científicas escolares. XXI Simpósio Nacional de Ensino de Física. 2015. 60

TAUCHEN, G. S. J. A. Educação em Ciências: epistemologias, princípios e ações educativas. Curitiba: Editora CRV, 2012. 62 